\title{
Turismo de Base Comunitária na Amazônia Legal brasileira: organização da atividade ou estratégia de marketing?
}

\section{Community Based Tourism in the Brazilian Legal Amazon: organization of the activity or marketing strategy?}

\author{
Abel Pojo Oliveira, Bárbara Pereira Carmona dos Santos
}

\begin{abstract}
RESUMO: O Turismo de Base Comunitária (TBC) vem sendo debatido como uma potencial boa maneira de desenvolvimento da atividade, sendo uma das frentes de contraposição ao chamado turismo de massa. Diante disso, este estudo busca discutir o conceito do TBC e os desdobramentos de sua prática enquanto organização da atividade e estratégia de marketing. Para tanto, foi realizada revisão bibliográfica e pesquisa de gabinete sobre experiências de TBC na Amazônia Legal brasileira. Dentre os resultados, percebeu-se que o TBC é eminentemente uma forma de organização da atividade turística, onde predomina o protagonismo de comunidades no planejamento e desenvolvimento da atividade, com fins a geração de renda e melhoria de sua qualidade vida, em seu território. Identificaram-se ainda nove destinos na Amazônia Legal mencionados como experiências que usam esse tipo de organização. Além disso, três desses: Pousada Uacari (AM), Ecoturismo comunitário no Polo Tapajós (PA) e Pousada Aldeia dos Lagos (AM) trabalham a base comunitária na perspectiva de estratégia de marketing. Estes divulgam maior estrutura para atendimento de turistas, inclusive com pousadas comunitárias e material promocional bilíngue (português e inglês), bem como inserção em sites de internet (próprios e/ou de parceiros) e redes sociais.
\end{abstract}

PALAVRAS CHAVE: Turismo de Base Comunitária; Marketing; Amazônia Legal.

\section{ABSTRACT}

Community Based Tourism (CBT) has been debated as a potential good way to develop the activity, being one of the fronts in opposition to the so-called mass tourism. By the way, this study seeks to deliberate the concept of TBC and the unfolding of its practice as an organization of the activity and marketing strategy. For this, a bibliographic review and cabinet research was carried out on the experiences of TBC in the Brazilian Legal Amazon. As results, it was perceived that the TBC is eminently a form of organization of the tourist activity which the protagonism of communities predominates in the planning and development of the activity, with the purpose of income generating and improving its quality of life in its territory. It was also identified nine destinations in the Legal Amazon mentioned as experiences that use this type of organization. In addition, three of these: Pousada Uacari (AM), Community Ecotourism at Polo Tapajós (PA) and Pousada Aldeia dos Lagos (AM) work the community base in the perspective of marketing strategy. These spaces divulge a larger structure to assist tourists, including community hostels and bilingual promotional material (Portuguese and English), as well as insertion in internet sites (own and / or partners) and social networks.

KEYWORDS: Community Based Tourism; Marketing; Legal Amazon.

Sociedade Brasileira de Ecoturismo. Rua Dona Ana, 138, Vila Mariana, São Paulo, SP - Brasil.

E-mail: rbecotur@sbecotur.org.br; Tel. (55-11) 99195-7685. 


\section{Introdução}

O Turismo de Base Comunitária (TBC) vem sendo cada vez mais discutido por estudiosos, profissionais da área e comunitários como uma alternativa para a geração de renda e melhoria da qualidade de vida de comunidades dos mais diversos países e regiões. O TBC é uma das formas de organização do turismo.

O turismo, por sua vez, é definido pela Organização Mundial do Turismo - OMT como as atividades realizadas pelas pessoas que viajam para fora de seu ambiente habitual, por menos de um ano consecutivo, motivadas por negócios, prazer, ou outros interesses pessoais, e que não sejam empregadas por uma organização no local visitado (UNWTO, 2019).

Porém, é importante compreendê-lo como "uma prática social, que envolve o deslocamento de pessoas pelo território e que tem no espaço geográfico seu objeto de consumo" (CRUZ, 2003, p. 05). Deste modo, a atividade turística propicia o consumo das áreas onde se desenvolve, gerando alterações de diversas naturezas e magnitudes nesses territórios.

As consequências danosas do chamado turismo de massa, que atende basicamente a interesses mercadológicos, alcançam os campos ambiental, social e mesmo econômico; e são amplamente discutidas por autores e organizações em âmbito internacional, especialmente depois do aumento da preocupação ambiental na década de 1970 (SWARBROOKE, 2000; CRUZ, 2003).

Entretanto, como bem avalia Irving (2009, p. 108)

O turismo define as suas próprias regras e traz a fantasia e o sonho a uma realidade de valores contraditórios, em uma sociedade globalizada. Mas o fenômeno turístico e o processo de globalização são irreversíveis, e o desafio para um horizonte desejável não mais se traduz na discussão de incompatibilidades e riscos, mas na concepção e desenvolvimento de alternativas criativas e inovadoras de um tipo de turismo que internalize a variável local e as identidades envolvidas como elemento central de planejamento.

Nesse sentido, as experiências de Turismo de Base Comunitária (TBC) vêm sendo debatidas como uma potencial boa maneira de desenvolvimento da atividade, sendo uma das frentes de contraposição ao denominado turismo de massa.

Ao tempo que o TBC é compreendido como uma maneira de organização da atividade turística fundamentada no protagonismo de comunidades que recebem turistas em seus territórios, ele por vezes é também empregado como estratégia para a promoção e venda de um determinado destino ou roteiro turístico. Neste contexto, surgem as perguntas-problemas que motivaram este estudo: o TBC é um modo de 
organização da atividade ou uma estratégia de marketing? Como isso vem sendo trabalhado em destinos de TBC na Amazônia Legal brasileira?

Diante disso, o objetivo geral deste estudo é discutir o conceito do TBC e os desdobramentos de sua prática, enquanto organização da atividade e como estratégia de marketing. Este objetivo desdobra-se em três específicos: i) entender o conceito e os elementos relacionados à organização do TBC; ii) analisar aspectos relacionados ao marketing turístico; e iii) verificar o modo como o TBC está sendo divulgado/vendido na Amazônia Legal brasileira.

Para alcançar tais objetivos, optou-se por revisão bibliográfica sobre os temas Turismo de Base Comunitária e Marketing, bem como por pesquisa de gabinete sobre os destinos de base comunitária divulgados pela Red de Turismo Comunitario de America Latina - Redturs ${ }^{1}$ que estão localizados na Amazônia Legal brasileira².

Vale ressaltar que durante a busca não foi localizada outra rede ou qualquer entidade que concentrasse as informações sobre destinos de TBC na Amazônia Legal. Outro destaque é que as informações disponíveis no site da Redturs só tinham como opção de idiomas o inglês e o espanhol.

Identificados nove destino de TBC na Amazônia Legal, dentre os 37 listados na Redturs, buscou-se investigar quais possuem trabalho de divulgação em websites próprios ou redes sociais (Facebook e Instagram), se estão disponíveis pacotes ou roteiros para compra em websites de viagens, quem os divulga, se existe algum tipo de menção específica sobre o mesmo tratar-se de uma experiência de TBC, quais os idiomas nos quais os conteúdos estão disponíveis e outras informações que se percebessem relevantes.

A importância desta investigação reside em proporcionar maior compreensão sobre essas experiências, tanto do ponto de vista de sua organização quanto de seu trabalho de venda e divulgação, lembrando que o turismo é uma atividade econômica e que o seu realizar sempre terá interface com o mercado.

Este estudo está estruturado nesta introdução mais cinco capítulos: uma compreensão conceitual sobre o TBC e sua organização; uma abordagem dos elementos relacionados à organização do TBC; uma análise do TBC como uma estratégia de marketing; a apresentação dos resultados e discussão deles; e as considerações finais.

\section{Turismo de Base Comunitária: discussão conceitual}

O desafio em melhorar a própria qualidade de vida, seja na zona urbana ou na zona rural, tem levado muitas comunidades à busca por atividades econômicas alternativas, que possam gerar renda e desenvolvimento em seu território. Nesse sentido, o turismo tem sido pautado como saída para elas. 
Maldonado (2009) afirma que o mesmo denomina como Turismo Rural Comunitário (TRC) iniciou recentemente na América Latina, sendo as primeiras incursões a comunidades isoladas datadas de meados dos anos 1980. Em território brasileiro, de acordo com Sansolo e Bursztyn, (2009), é a partir da década de 1990 que o turismo passa a ser uma atividade não agrícola que agrega valor às atividades de agricultores familiares.

De acordo com informações obtidas junto a Redturs - Red de Turismo Comunitario de America Latina, atualmente existem 322 destinos comunitários em toda a América Latina. No Brasil, são 37, conforme Quadro 1, abaixo, dividido por região. O país fica atrás apenas do Equador, que possui 52 destinos dessa natureza.

Quadro 1: Destinos comunitários do Brasil registrado na Redturs.

Table 1: Community destinations in Brazil registered with Redturs.

\begin{tabular}{|c|c|c|c|}
\hline \multicolumn{4}{|c|}{ DESTINOS COMUNITÁRIOS NO BRASIL } \\
\hline REGIÃO NORTE & UF & $\begin{array}{l}\text { Centro de turismo de Santo Amaro de } \\
\text { Maranhão }\end{array}$ & MA \\
\hline Pousada Aldeia dos Lagos, Silves & AM & $\begin{array}{l}\text { Turismo comunitário em Porto de } \\
\text { Galinhas }\end{array}$ & $\mathrm{PE}$ \\
\hline Pousada Uacari & AM & Turismo no povoado de Terra Caída & SE \\
\hline Turismo Comunitário no Rio Unini & AM & Turismo solidário e cultura popular & $\mathrm{RN}$ \\
\hline Turismo comunitário no Rio Negro & AM & Turismo comunitário na llha Caieiras & ES \\
\hline $\begin{array}{l}\text { Cooperativa de turismo comunitário } \\
\text { em Curuçá }\end{array}$ & PA & REGIÃO CENTRO-OESTE & UF \\
\hline $\begin{array}{l}\text { Ecoturismo comunitário no Polo } \\
\text { Tapajós }\end{array}$ & $\mathrm{PA}$ & $\begin{array}{l}\text { Valorando a cultura popular em } \\
\text { Pirenópolis }\end{array}$ & GO \\
\hline Projeto VEM & PA & Guardiões do pantanal & MT \\
\hline Turismo comunitario en Taquaruçu & TO & REGIÃO SUDESTE & UF \\
\hline REGIÃO NORDESTE & UF & Turismo comunitário em Brumadinho & $\begin{array}{l}M \\
G\end{array}$ \\
\hline Ecoturismo em Cassurubé & $\mathrm{BA}$ & $\begin{array}{l}\text { Caiçaras, indígenas e quilombolas: } \\
\text { turismo cultural }\end{array}$ & RJ \\
\hline Projeto Trilhas de Lençóis & BA & Revive Paquetá & $\mathrm{RJ}$ \\
\hline $\begin{array}{l}\text { Turismo de base comunitária em } \\
\text { Lençóis }\end{array}$ & BA & Ecoturismo comunitário na Rota de Ouro & $\begin{array}{l}\mathrm{RJ} / \\
\mathrm{SP}\end{array}$ \\
\hline $\begin{array}{l}\text { Turismo comunitário na Costa do } \\
\text { Cacau }\end{array}$ & $\mathrm{BA}$ & Turismo comunitário em Santa Catarina & SP \\
\hline $\begin{array}{l}\text { Casa Grande, Memorial do Homem do } \\
\text { Kariri, Nova Olinda }\end{array}$ & CE & Turismo comunitário em Juquitiba & SP \\
\hline Ponta Grossa & CE & REGIÃO SUL & UF \\
\hline Prainha do Canto Verde (Ceará) & CE & $\begin{array}{l}\text { Ecoturismo comunitário no Litoral Norte } \\
\text { de Paraná }\end{array}$ & PR \\
\hline Rede de ecoturismo para a vida & CE & Comunidades do Rio Sagrado & PR \\
\hline $\begin{array}{l}\text { Turismo comunitário: afirmando } \\
\text { identidades }\end{array}$ & CE & Boas práticas no turismo comunitário & RS \\
\hline $\begin{array}{l}\text { Turismo comunitário em Tijuca Boa } \\
\text { Vista }\end{array}$ & CE & Rota Caminhos Rurais & RS \\
\hline $\begin{array}{l}\text { Turismo comunitário e solidário em } \\
\text { Assaré de Patativa }\end{array}$ & CE & $\begin{array}{l}\text { Turismo comunitário com Mulheres de } \\
\text { Joinville }\end{array}$ & SC \\
\hline
\end{tabular}

Fonte: Elaborado pelos autores a partir de dados de Redturs (2019).

Source: Prepared by the authors from data from Redturs (2019). 
Para Maldonado (2009), diversos fatores estão associados à origem do TBC na América Latina, tais como: pressões mundiais do mercado turístico; busca de superação de pobreza crônica por algumas comunidades; papel relevante das pequenas e microempresas no desenvolvimento econômico local e na diversificação da oferta turística; e as estratégias políticas do movimento indígena e rural para preservar seus territórios ancestrais na ótica de incorporação aos processos de globalização com sua própria identidade.

Debruçados também sobre o estudo do TBC sob o ponto de vista conceitual em diversos países latino-americanos, Sansolo e Bursztyn, (2009, p. 147) observam que "os componentes de conservação ambiental e valorização da identidade cultural sustentam esta proposta de turismo, bem como a geração de benefícios diretos para as comunidades receptoras". Para os autores, esses benefícios viriam da organização e controle da atividade por parte da comunidade.

Em consonância com essa ideia, porém em uma perspectiva mais social, Irving (2009, p. 111) analisa que

\begin{abstract}
o turismo de base comunitária, portanto, tende a ser aquele tipo de turismo que, em tese, favorece a coesão e o laço social e o sentido coletivo de vida em sociedade, e que por esta via, promove a qualidade de vida, o sentido de inclusão, a valorização da cultura local e o sentimento de pertencimento.
\end{abstract}

Deste modo, sem contrapor o conceito apresentado por Sansolo e Bursztyn, (2009), a acepção de Irving (2009) ressalta aspectos relacionados com a coesão social, remarcando que antes de tudo, esse tipo de turismo é assim designado não porque ocorre em uma comunidade enquanto é visitada por turistas, mas porque surge de algo comum, de algo coletivo.

Ainda de acordo com Irving (2009), algumas premissas centrais emergem na releitura sobre o turismo de base comunitária: base endógena da iniciativa e desenvolvimento local; participação e protagonismo social no planejamento, implementação e avaliação de projetos turísticos; escala limitada e impactos sociais e ambientais controlados; geração de benefícios diretos à população local; afirmação cultural e interculturalidade; e o "encontro" como condição essencial.

Essas premissas falam bastante sobre a essência desse tipo de turismo, pois em muitos casos as discussões sobre o tema estão especialmente centradas nos aspectos relacionados com a percepção de benefícios pelas comunidades a partir da atividade, geralmente traduzidos em geração de renda.

Já em outra sistematização do conceito de TBC, Costa Novo (2011, p. 45) afirma que 
[...] o turismo de base comunitária é uma modalidade de turismo em que prevalece o protagonismo das comunidades no oferecimento de atividades turísticas realizadas nos territórios que ocupam, obedecendo a princípios ambientais e culturais autoestabelecidos, promovendo, sobretudo, a valorização da participação e da organização comunitária, do associativismo, da ética, com vistas ao desenvolvimento local e à preservação de sua cultura.

Nesse entendimento, Costa Novo (2011) aborda quatro elementos que merecem destaque ao se pensar em TBC: o protagonismo das comunidades, o uso do território o qual ocupam respeitando valores ambientais e culturais, a geração de benefícios para a comunidade e a preservação de sua cultura. De um modo geral, esses elementos perpassam pelas concepções de Irving (2009) e Sansolo e Bursztyn, (2009), e se revelam marco importante para este estudo.

Para Costa Novo (2011), a proposta do turismo de base comunitária é a promoção de mudanças significativas, protagonizada pela comunidade em seu próprio lugar, em relação a processos de exclusão econômica, social, educacional e outros. Por isso, é pertinente salientar que a ideia do TBC, em sua essência, não reclama apenas a participação da comunidade, mas sim 0 seu protagonismo no pensar/agir/refletir sobre a atividade turística desenvolvida em seu território.

\section{Elementos que compõe a organização do TBC}

$\mathrm{Na}$ proposta de organização do Turismo de Base Comunitária, é comum que as comunidades recorram a agentes externos que possam colaborar com esse processo, como o poder público, o setor privado e as organizações do terceiro setor, entretanto, Sansolo e Bursztiyn (2009) e Costa Novo (2011) enfatizam o aporte técnico e o apoio financeiro deste último agente.

Importante destacar que existem várias possibilidades de as comunidades participarem e/ou desenvolverem a atividade turística. Nesse sentido, a partir de seu olhar sobre a América Latina, Maldonado (2009) sistematiza a participação das comunidades no que chama de "indústria do turismo" em seis modalidades, conforme Quadro 2, abaixo: 
Quadro 2: Participação das comunidades no turismo e suas principais características.

Table 2: Community participation in tourism and its main characteristics.

Modo de participação

1) Autogestão do negócio turístico

2) Parceria de negócios

com uma empresa privada

3) Parceria comercial com operadoras de turismo

4) Concessão de recursos comunitários em usufruto

5) Trabalho assalariado para operários

6) Formas híbridas

\section{Principais características}

A comunidade decide trabalhar com turismo em seu território, participa de todas as etapas: planejamento, execução, promoção/venda dos produtos e gestão

Há um contrato legal por tempo determinado entre investidor e comunidade, existe repartição de benefícios e obrigações e, ao final, o contrato pode ser renovado ou não

Existe um acordo onde a agência envia turistas e a comunidade os recebe, presta serviços, é remunerada por isso, e muitas vezes recebe apoio da empresa para capacitação e infraestrutura, mas esta controla o fluxo

As comunidades cedem para uso temporário os recursos naturais de seu território e alguns serviços culturais em troca de benefícios acordados com empresas de turismo

Algumas famílias participam a título pessoal do apoio à realização de turismo na região (fora da comunidade) em troca de remuneração e em caráter temporário, não existindo projeto comunitário

Agências levam turistas para a comunidade e ao mesmo tempo contrata esta para prestação de serviços. A comunidade realiza investimentos próprios. Há um sistema de rodízio para que todos os membros da comunidade interessados possam ser contratados

Fonte: Elaborado pelo autor a partir de dados de Maldonado (2009).

Source: Prepared by the authors from data from Maldonado (2009).

Em linhas gerais, a primeira possibilidade apresentada no quadro acima (autogestão do negócio turístico), refere-se ao que se pensaria como cenário ideal para o turismo de base comunitária, pois a comunidade possui - poder decisório sobre os rumos da atividade. A quinta (trabalho assalariado para operários) seria a maneira mais passiva, sendo relevante para algumas famílias, mas de pouca abrangência em termos de comunidade.

Outra questão que merece destaque é que a proposta de Maldonado (2009) não trata de uma espécie de escada, onde a comunidade precisaria passar por cada etapa até a autogestão. Pode-se compreendê-la como possíveis arranjos que, inclusive podem ter natureza múltipla (formas híbridas) e que são influenciadas pela comunidade, pelos agentes externos e pelos próprios turistas. $\mathrm{O}$ que o quadro nos mostra é que as experiências de TBC não são homogêneas; elas possuem características próprias e diversas.

É importante avultar que o TBC não é um segmento do turismo ${ }^{3}$, como o é o Ecoturismo, por exemplo. Ele é uma forma de organização do turismo pautada nos princípios de sustentabilidade (ambiental, social e econômica), mas que tem como bojo principal o protagonismo da comunidade no seu desenvolvimento e não apenas no contato com os 
turistas, como ocorre em algumas atividades, inclusive de Ecoturismo ou de outros segmentos.

Esse tipo de turismo pode proporcionar experiências associadas a alguns segmentos do turismo. Pode-se pensar, por exemplo, no Ecoturismo de base comunitária, onde o turista busca o contato com a natureza, mediante uma atitude responsável, porém com o diferencial de ter a comunidade receptora protagonizando a organização do seu momento de lazer ou de parte dele.

Essa diferença fica mais clara se pensarmos que uma agência de turismo pode promover a visita e o contato do turista com uma comunidade sem envolver esta no planejamento da atividade e na participação da maior parte dos benefícios. Neste caso seria um turismo convencional, agenciado, até mesmo de massa, mas não seria de base comunitária.

Por outro lado, se esta mesma comunidade se organiza para decidir se e em que termos ocorrerá o contato com o turista, se haverá parceria com uma agência e de que modo os lucros e responsabilidades serão repartidos, bem como quais aspectos de sua cultura e ambiente serão proporcionados ao turista conhecer; ou seja, se os comunitários saírem de uma condição de "atrativo" para serem planejadores da atividade, neste caso pode-se considerar o turismo de base comunitária.

Percebe-se, deste modo, que o que determina que uma experiência seja de TBC não é a vinculação a um segmento específico do turismo ou a presença/ausência de uma agência de turismo ou de outro agente externo, como agentes públicos ou do terceiro setor, mas sim o grau de engajamento e de poder decisório de uma comunidade sobre a realização da atividade turística em seu território.

Diante dessa reflexão, outra questão interessante de ser abordada sobre o tema, é que muitas vezes falta o entendimento de que

o turismo não deve competir nem, e menos ainda, suplantar as atividades tradicionais que têm garantido a sobrevivência de tais povos. É concebido como um complemento ao progresso econômico e ocupacional para potencializar e dinamizar as atividades tradicionais que as comunidades controlam com imensa sabedoria e maestria (MALDONADO, 2009, p. 30).

A percepção do turismo como "tábua de salvação" pode gerar grandes frustrações no desenvolver da atividade por parte de comunidades, pois muitos comunitários podem abandonar suas atividades (pesca, lavoura, extrativismo) para dedicar-se ao turismo, porém sem obter o êxito esperado e, ainda, afastarem-se de seu modo tradicional de vida e reprodução, que são condições essenciais de sua existência. 
Além disso, outro motivo que pode gerar esse sentimento é quando acontece o que Holanda (2016) chama de empresarização do TBC. Segundo a autora,

\begin{abstract}
nesse cenário global, nem as iniciativas de turismo de base comunitária (TBC), que emergiram na contramão do turismo de massa, escapam dessa realidade e estão sendo impelidas a adotar práticas características do mundo empresarial, subordinadas a critérios de eficiência e competitividade, pressupostos estes, muitas vezes, distantes dos objetivos das comunidades tradicionais que lidam com aspectos mais substantivos da vida organizada (p. 252)
\end{abstract}

Ao buscar tornarem-se competitivas no mercado turístico, algumas comunidades se veem obrigadas a manter rotinas de profissionalização e de atividades administrativas e burocráticas pertinentes a esse tipo de empreitada, porém que as afastam do seu modo de viver tradicional, gerando insatisfação para as mesmas.

Tão logo, pensar no TBC não deve ser sinônimo de transformar a comunidade em uma empresa. O modelo empresarial está voltado para o lucro financeiro e as comunidades, embora também queiram percebê-lo, possuem outras necessidades, como de conexão com a natureza e com a sua cultura, aspectos estes que precisam ser tratados como prioritários por elas, pelos apoiadores externos da atividade e pelos turistas.

Diante disso, o TBC precisa ser pautado na compreensão do que é importante para a comunidade e para a sua manutenção enquanto comunidade, nisso embutidos seus valores e subjetividade. Uma comunidade não precisa necessariamente desenvolver o TBC, mas se decidir fazê-lo é relevante refletir sobre esses diversos aspectos que o compõem.

\title{
Planejamento do turismo, marketing e TBC
}

Todo planejamento tem uma missão, ou seja, o ponto ou realidade que se deseja atingir com o cumprimento de metas e ações nele estabelecidas, e essa ferramenta é utilizada nas mais diversas áreas. Quando relacionamos a teoria existente com o planejamento do setor turístico, algumas características podem ser observadas. Uma dessas características é o diagnóstico.

Ruschmann (1997) ressalta que para a realização eficaz do planejamento turístico de uma localidade, o diagnóstico tem por função a identificação do produto, da imagem divulgada e do diferencial. Nesse mesmo estudo a autora faz referência à necessidade de se verificar a imagem da oferta e da sua qualidade para a demanda real. 
Sempre que o objeto de estudo é o turismo, e no caso deste trabalho mais especificamente o TBC, o item imagem é de suma relevância, pois trata-se de uma área intimamente ligada ao imaginário, ao desconhecido, ao lúdico. Em alguns casos, a ideia que é construída do destino ou a imagem prévia que é colocada ao futuro visitante, prediz como vai funcionar tudo que o turista vai encontrar na localidade para onde se destina.

Considerando que o turismo é uma atividade econômica de grade importância para a maioria dos países, o planejamento desta atividade em uma localidade passa inevitavelmente pelo marketing. Logo, é deste a função de planejar e alcançar a imagem pretendida na mente de seus clientes potenciais. E no caso do TBC estamos falando não só da importância da atividade para o país, mais sim diretamente para a comunidade, de modo econômico e social.

Nesse momento que é necessário abordar o planejamento dessa atividade pelo prisma da administração de marketing. Kotler (1980, p.34) nos apresenta a mesma como

a análise, o planejamento, a implementação e o controle de programas destinados a realizar as trocas desejadas com mercados-alvo com o propósito de atingir as metas da organização, em termos das necessidades e desejos dos mercados-alvo, usando eficazmente o preço, a comunicação e a distribuição, a fim de informar, motivar e servir o mercado.

A ferramenta que permite que esse modelo de planejamento seja colocado em prática é o plano de marketing, e dentre as muitas maneiras que um plano de marketing dispõe para que possa atingir este objetivo, a mais eficaz em uma sociedade saturada de comunicação por todos os lados, é a do posicionamento da imagem do produto/destino na mente de seus clientes potenciais.

Ao analisar o marketing no contexto desse trabalho, é possível identificar quando o mesmo lança mão de um conceito essencial no que trata de desenvolver ideias de consumo: o posicionamento. Este se apresenta como algo que é preciso se associar as características de um produto a ser posicionado, ou seja, às informações que já estejam na mente de seu público em potencial. Deste modo, o mesmo irá assimilar as mensagens sobre seu produto, e não as rejeitar como faz com a maior parte das informações que recebe todos os dias.

Quando se pensa na aplicabilidade da ferramenta de posicionamento para o desenvolvimento do TBC, trata-se não só de uma ferramenta de alocação de ideias, mas também, de uma maneira de focar exatamente 0 público pretendido em suas várias características, já que diz respeito a um produto extremamente específico, desde a sua concepção até sua comercialização. 
A exemplo disso, o planejamento de marketing deve encarregar-se de identificar ou mesmo estabelecer a que segmento de mercado o produto/destino pretende atingir. Para Montejano (2001, p. 72) a segmentação de mercado

configura-se graças a uma série de produtos turísticos com tipologia particular relacionada com os recursos turísticos que têm qualquer lugar ou espaço turístico. Essa tipologia vem acompanhada por um segmento da população mais ou menos amplo que, por suas motivações e necessidades, se sente atraída por tal produto ou serviço que oferece o destino turístico.

Todo este planejamento e segmentação, para o alcance dos resultados pretendidos, deve ter como ponto principal a comunicação, já que ela está diretamente relacionada ao produto turístico na esfera entre a elaboração do produto turístico e o seu consumo - a componente da oferta e da procura.

A criação e transmissão de uma dada mensagem sobre 0 produto/destino turístico, por um determinado emissor, de acordo com um objetivo estipulado, utilizando o canal mais adequado e dirigida a um receptor específico, é um processo que desencadeia a conexão entre a oferta (produto/destino) e a procura (atual ou potencial turista).

Segundo Kotler (2000), dentre as ferramentas de marketing a responsável por realizar a tarefa de "conquistar a cabeça do cliente" é a comunicação. Para se comunicar bem, a empresa deve saber o que dizer, para quem dizer e com que frequência dizer. Ainda segundo o autor, as cinco formas essenciais de comunicação que formam o mix de comunicação em marketing são a propaganda, promoção de vendas, relações públicas e publicidade, vendas pessoais e marketing direto.

Já em um livro que traz as ferramentas de comunicação aplicadas ao setor de turismo, a divisão apresentada por Cobra (1992) das ferramentas de comunicação é: propaganda; promoção de vendas; relações públicas; venda pessoal, pela internet e campanhas de marketing direto; e o comércio eletrônico.

Ainda segundo Cobra (1992), a comunicação de um serviço turístico pode ter três características. A primeira citada por ele foi a "casual - quando um fato ou evento turístico é notificado sem que haja o pagamento ou a interferência", a "informativa - que é um comunicado ao público" e a "persuasiva - quando o objetivo do anunciante é a venda do produto ou serviço turístico" (COBRA 1992, p. 29).

Focando nessas três características de comunicação que o turismo pode planejar, o TBC será trabalhado em sua maioria entre as características informativa e a persuasiva, uma vez que o a casual 
geralmente não é planejável, como a decisão de um município de realizar a programação do aniversário da cidade em um dado local (que é um atrativo trabalhado pelo TBC) e realizar uma ampla divulgação, que gera uma 'divulgação casual' ao local que trabalha o TBC por ser aniversário da cidade e não por ele em si. Deste modo, a maneira com que ele será abordado nos possibilita várias análises sobre o quanto esse "diferencial" está sendo apresentado ou mesmo colocado como ponto central do produto.

Ainda tratando de comunicação, Kotler (2000, p. 570) apresenta a base do modelo de comunicação, e segundo o autor esse modelo tem nove elementos sendo que

dois deles representam as principais partes envolvidas na comunicação - emissor e o receptor. Outros dois representam as principais ferramentas de comunicação: a mensagem e o meio. Outros quatro elementos representam as principais funções da comunicação - codificação, decodificação, resposta e feedback. O último elemento no sistema é o ruído (mensagens aleatórias e concorrentes que podem interferir na comunicação pretendida).

A partir desses nove elementos, tem-se o conceito de posicionamento, que surge de uma necessidade do mercado, diante da avalanche de mensagens de comunicação a qual as pessoas são expostas diariamente. Os meios de comunicação evoluem de maneira frenética, porém, o cérebro tem um limite de absorção que hoje está muito aquém da quantidade dessas informações.

Deste modo Al Reis e Jack Trout, em artigos escritos em 1972 para uma revista especializada chamada Advertising Age, nos Estados Unidos, lançam este conceito ao mercado. Conceito este que só foi lançado em forma de livro no Brasil em 1989, pelos mesmos autores dos artigos, intitulado Posicionamento de Marca, onde os autores definem posicionamento como "o que você faz na mente do cliente em perspectiva. Ou seja, você posiciona o produto na mente do cliente em potencial" (REIS; TROUT, 1989, p. 42).

As justificativas dadas pelos autores para a eficácia deste conceito no mercado é dada por argumentos como os de que "ser criativo, criar alguma coisa que já não exista na mente, está se tornando cada vez mais difícil, se não impossível." Os autores expõem que "para se defender do volume de comunicação diária, a mente filtra e rejeita muita informação que Ihe chega [...] e tentar mudar a mente é o caminho certo para o desastre na propaganda" (REIS; TROUT, 1989, p. 22).

Baseado nisso, o posicionamento vem com a ideia de que é preciso se associar às características de um produto a ser posicionado, às informações que já estejam na mente de seu público em potencial, e deste 
modo, o mesmo irá assimilar as mensagens sobre seu produto, e não rejeitá-las, como faz com a maior parte das informações que recebe todos os dias.

Essa descrição nos permite apontar o ponto de partida para toda a comunicação a ser implementada sobre um destino que esteja trabalhando o TBC. Se as pessoas a serem alcançadas devem ter em seus valores os mesmos trabalhados por esse tipo de turismo, o público a ser atingido está bem definido.

Outro argumento que acompanha os já citados é o de que, para se implementar uma campanha publicitária com as características da teoria do posicionamento, o custo e o tempo despendidos são bem menores do que seriam ao se lançar uma nova marca, produto ou ideia no mercado. Sendo essa outra característica relevante, dada a natureza das decisões e dos investimentos nesse tipo de produto.

Ainda segundo esses autores, a estratégia de posicionamento pode seguir quatro possíveis orientações, que são as de reforçar a sua atual posição na mente do consumidor, conquistar uma posição não-ocupada, destituir ou reposicionar a concorrência, ou ainda a do clube exclusivo, por exemplo, as três maiores. Essa normalmente é criada pela terceira em seu segmento (REIS; TROUT, 1989).

Kotler (2000, p. 142) coloca em sua obra que o conceito de posicionamento "é o ato de desenvolver a oferta e a imagem da empresa para ocupar um lugar destacado na mente dos clientes-alvo". E aborda ainda que as diferenças estratégicas de posicionamento disponíveis são as de posicionamento por: atributo, benefício, aplicação ou utilização, usuário, concorrente, categoria de produtos e por qualidade ou preço.

A partir desse conceito a categorização do TBC pode ser feita em sua plenitude. Os elementos apresentados pelo autor oferecem uma gama de variáveis que atendem a delimitação do possível perfil consumidor em uma vasta descrição, e que permite que, independente da gama de conhecimento que todos os envolvidos ligados a gestão do empreendimento tenham, o conceito de posicionamento possa ser aplicado.

\section{Resultados e discussão}

Dentre os 37 destinos de turismo de base comunitária no Brasil listados no site da Redturs, nove estão situados na Amazônia Legal, sendo quatro no Amazonas, três no Pará, um no Tocantins e um no Mato Grosso, conforme Quadro 3, abaixo. Nos estados do Acre, Roraima, Rondônia, Amapá e Maranhão 4 não foram mencionados destinos de TBC. 
Quadro 3: Destinos de TBC listados no site da Redturs e localizados na Amazônia Legal.

Table 3: CBT destinations listed on the Redturs website and located in the Legal Amazon.

\begin{tabular}{|l|l|}
\hline Destino de TBC & UF \\
\hline Pousada Aldeia dos Lagos, Silves & AM \\
\hline Pousada Uacari & AM \\
\hline Turismo Comunitário no Rio Unini & AM \\
\hline Turismo comunitário no Rio Negro & AM \\
\hline Cooperativa de turismo comunitário em Curuçá & PA \\
\hline Ecoturismo comunitário no Polo Tapajós & PA \\
\hline Projeto VEM - Viagem Encontrando Marajó & PA \\
\hline Turismo comunitário em Taquaruçu & TO \\
\hline Guardiões do pantanal & MT \\
\hline
\end{tabular}

Fonte: Elaborado pelos autores.

Source: Prepared by the authors.

Dos nove pesquisados, apenas dois possuem site próprio: Pousada Uacari (AM) e Ecoturismo comunitário no Polo Tapajós (PA). Vale ressaltar que a Pousada Aldeia dos Lagos (AM) não possui site próprio, porém é o único dentre os destinos pesquisados que aparece em vários sites e aplicativos de reservas online (Portal Férias, Hotel in Site, Mercado, Viagens.com e Kekanto).

Outro dado relevante acerca da disponibilidade de informações desses lugares na internet é o fato de que são esses últimos três destinos que apresentam resultados nas buscas em perfis de redes sociais como 0 Facebook e o Instagram. Quando se analisa por meio de quais canais são divulgados/comercializados cada um dos nove destinos, o resultado não difere do até então apresentado.

Deste modo, pode-se verificar que três possuem meios próprios de divulgação e utilizam claramente da comunicação informativa e persuasiva mencionadas por Cobra (1992). Os outros seis estão mencionados somente no site da Redturs.

Quando se trata de entidade atuante na divulgação dos destinos, além da Redturs, a Pousada Aldeia dos Lagos (AM) conta com a Associação de Silves para Preservação Ambiental e Cultural (Aspac); a Pousada Uacari (AM) conta com o Instituto Mamirauá; e o Ecoturismo comunitário no Polo Tapajós com a ONG Saúde e Alegria e com a Cooperativa de Turismo e Artesanato da Floresta -Turiarte.

Quando se busca menção ao TBC no trabalho de divulgação dos nove destinos pesquisados é possível verificar que todos estão nessa categoria no site da Redturs, porém os três citados acima fazem menção ao TBC também em seus demais canais de comunicação, ressaltando-o como algo peculiar, como um diferencial em relação a outros destinos turísticos.

Nesta última análise, uma particularidade surge no Projeto VEM (PA), que embora mencione no site da Redturs a sua comercialização pela 
operadora Turismo Consciente, ao investigar o destino no site da referida empresa, a mesma não faz menção ao destino como sendo de TBC e o trabalha como um roteiro conjugado denominado Belém e llha do Marajó, sendo que o projeto está localizado em uma cidade desta ilha.

Diante disso, percebe-se que embora a Pousada Aldeia dos Lagos (AM), a Pousada Uacari (AM), o Ecoturismo comunitário no Polo Tapajós (PA) e o Projeto VEM (PA) trabalhem algum nível de divulgação voltada para a comercialização, apenas os três primeiros posicionam-se como destinos de TBC junto aos potenciais turistas nos termos de Reis e Trout (1989). Desta feita, esses três destinos além de tratar o TBC enquanto organização da atividade, também o utilizam enquanto estratégia de marketing.

Finalmente, ao analisarmos quais dos nove destinos lançam mão de mais de um idioma em seu material de divulgação, apenas dois são bilíngues: a Pousada Uacari $(\mathrm{AM})$ e o Ecoturismo comunitário no Polo Tapajós (PA), ambos em português e inglês. Isso denota que há um direcionamento a um segmento de clientes em potencial, ou seja, turistas estrangeiros.

Neste ponto, vale ressaltar que não foi possível localizar uma rede ou qualquer outra fonte que concentrasse as informações sobre destinos de TBC na Amazônia Legal no idioma português, pois o Redturs só apresenta suas informações em inglês e espanhol, o que reforça a ideia anteriormente apresentada.

\section{Considerações Finais}

A partir das discussões apresentadas, pode-se perceber que 0 turismo de base comunitária - TBC é eminentemente uma forma de organização da atividade turística, onde predomina o protagonismo de comunidades no planejar e desenvolver da atividade, com fins a geração de renda e melhoria de sua qualidade vida, em seu território.

Essa forma de organização muitas vezes é realizada a partir de estímulo, apoio ou mesmo financiamento externo, a exemplo de órgãos públicos, organizações não governamentais e empresas privadas. Vale destacar que para ser de base comunitária, o turismo não precisa excluir sujeitos externos, mas a comunidade precisa ter autonomia sobre esse processo.

Outro aspecto fundamental sobre a questão é perceber que o simples fato de o turista manter contato com a comunidade durante sua visita não significa automaticamente que este turismo é de base comunitária, pois para que o seja depende do engajamento e poder de decisão da comunidade no planejamento, execução e avaliação da comunidade.

Observou-se também que uma vez que o turismo passa a receber 0 qualificativo 'base comunitária', isso significa um diferencial e pode ser trabalhado na perspectiva do marketing, com fins ao alcance de uma 
demanda que tenha esse interesse específico. Com isso, essa qualificação do turismo enquanto uma atividade de base comunitária promove 0 posicionamento do produto na mente do consumidor em potencial, no caso o turista.

Nesse sentido, ao divulgar um destino de turismo de base comunitária, este, que em primeira instância é uma forma de organização da atividade, passa a ser também estratégia para alcançar o turista que deseje ter uma experiência com essa peculiaridade.

Nesse contexto, a partir da investigação de nove destinos de TBC listados no site da Redturs e localizados na Amazônia Legal brasileira, notou-se que apenas três: Pousada Uacari (AM), Ecoturismo comunitário no Polo Tapajós (PA) e Pousada Aldeia dos Lagos (AM) trabalham a base comunitária na perspectiva de estratégia de marketing, embora os nove destinos abordados no estudo a tenham como forma de organização. Conclui-se que nos três casos em que existe uma clara organização administrativa dos destinos de TBC, as ferramentas de comunicação com 0 mercado pretendido são devidamente aplicadas.

Ao que se pôde constatar, estes três destinos divulgam maior estrutura para atendimento do turista, inclusive com pousadas comunitárias e material promocional bilíngue (português e inglês), bem como inserção em websites e redes sociais. Além disso, a atuação de organizações não governamentais externas à comunidade e o surgimento de organizações sociais de comunitário, com fins à gestão da atividade turística, também foi constatada.

Vale ressaltar que a maneira com que cada um dos três destinos citados acima, lança mãos do conceito de TBC em suas estratégias de marketing se mostrou extremamente distinta, e que apenas no caso da Pousada Uacari - AM o visitante tem previamente uma clara descrição do que é o TBC e de como essa pousada lida com ele.

\section{Referências}

BRASIL. IBGE. Amazônia Legal. Disponível em: <www.ibge.org.br>. Acesso em: 22 ago. 2018a.

BRASIL. Ministério do Turismo. Glossário do turismo: compilação de termos publicados por Ministério do Turismo e Embratur nos últimos 15 anos. 1ㄹe edição. Brasília: Ministério do Turismo, 2018b.

COBRA, M. Administração de Marketing. 2. ed. São Paulo: Atlas, 1992.

COSTA NOVO, C. B. M. Turismo Comunitário na Região Metropolitana de Manaus (AM): caracterização e análise crítica. 2011. 141f. Dissertação (Mestrado). Faculdade de Filosofia, Letras e Ciências Humanas, Universidade de São Paulo, São Paulo, 2011.

CRUZ, R.C.A. Introdução à Geografia do Turismo. 2a Ed. São Paulo: Roca, 2003. 
HOLANDA, L.A. Empresarização do turismo de base comunitária. Caderno Virtual de Turismo. Rio de Janeiro, v. 16, n. 2, p. 249-262, ago. 2016.

IRVING, M.A. Reinventando a reflexão sobre turismo de base comunitária: inovar é possível? In: BARTHOLO, R.; SANSOLO, D.G.; BURSZTYN, I. Turismo de Base Comunitária: diversidade de olhares e experiências brasileiras. Rio de Janeiro: Letra e Imagem, 2009. P. 108-121.

KOTLER, P. Marketing. Edição compacta. Tradução: H. de Barros. São Paulo: Editora Atlas, 1980.

KOTLER, P. Marketing para o século XXI: Como criar, conquistar e dominar mercados / Tradução Bazán Tecnologia e lingüística. São Paulo: Futura,2000.305p

MALDONADO, C. O turismo rural comunitário na América Latina: gênesis, características e políticas. In: BARTHOLO, R.; SANSOLO, D.G.; BURSZTYN, I. Turismo de Base Comunitária: diversidade de olhares e experiências brasileiras. Rio de Janeiro: Letra e Imagem, 2009. P. 25-44.

MONTEJANO, J.M. Estrutura do Mercado turístico. $2^{\circ}$ ed. São Paulo: Roca, 2001.

REDTURS. Red de Turismo Comunitario de America Latina. Disponível em: <http://www.redturs.org/>. Acesso em 22 jan 2019.

RIES, A.; TROUT, J. (1989): Posicionamento: a batalha por sua mente. 20a ed. São Paulo: Makron Books.

RUSCHMANN, D. Turismo e Planejamento Sustentável: a proteção do meio ambiente. Campinas, SP: Papirus, 1997.

SANSOLO, D.G.; BURSZTYN, I. Turismo de base comunitária: pontencialidade no espaço rural brasileiro. BARTHOLO, R.; SANSOLO, D.G.; BURSZTYN, I. Turismo de Base Comunitária: diversidade de olhares e experiências brasileiras. Rio de Janeiro: Letra e Imagem, 2009. P. 142161.

SWARBROOKE, J. Turismo Sustentável: conceitos e impacto ambiental. São Paulo: Aleph, 2000.

UNWTO. World Tourism Organization. Glossary of tourism terms. Disponível em: <http://statistics.unwto.org/sites/all/files/docpdf/glossaryterms. pdf>. Acesso em: 29 jan 2019.

\section{Notas:}

1 Rede de comunidades campesinas e indígenas, instituições de apoio e profissionais que compartilham da concepção de desenvolvimento sustentável e propiciam a autogestão do turismo voltado para o protagonismo comunitário no planejamento, operação, supervisão e desenvolvimento de seus negócios (REDTURS, 2019) 
2 A Amazônia Legal foi criada inicialmente como área de atuação da Superintendência do Plano de Valorização Econômica da Amazônia (SPVEA), em 1953. Atualmente, ela corresponde à área dos Estados da Região Norte (Acre, Amapá, Amazonas, Pará, Rondônia, Roraima e Tocantins), acrescidos da totalidade do Estado de Mato Grosso e dos municípios do Estado do Maranhão situados a oeste do meridiano 44으 O (BRASIL, 2018a).

3 A segmentação do turismo é a "forma de organizar o turismo para fins de planejamento, gestão e mercado. Os segmentos turísticos podem ser estabelecidos a partir dos elementos de identidade da oferta e também das características e variáveis da demanda" (BRASIL, 2018b, p. 27).

${ }^{4}$ Porção do estado do Maranhão referente à Amazônia Legal.

${ }^{5} \mathrm{O}$ presente trabalho foi realizado com apoio da Coordenação de Aperfeiçoamento de Pessoal de Nível Superior - Brasil (CAPES) - Código de Financiamento 001.

Abel Pojo Oliveira: Instituto Federal de Educação, Ciência e Tecnologia do Pará, Bragança, PA, Brasil

E-mail: abelpojo@yahoo.com.br

Link para o currículo Lattes: http://lattes.cnpq.br/9973916653900973

Bárbara Pereira Carmona dos Santos: Instituto Federal de Educação, Ciência e Tecnologia do Pará, Conceição do Araguaia, PA, Brasil

E-mail: barbara.turismo@gmail.com

Link para o currículo Lattes: http://lattes.cnpq.br/4801681723894627

Data de submissão: 23 de março de 2019

Data de recebimento de correções: 12 de maio de 2019

Data do aceite: 12 de maio de 2019

Avaliado anonimamente 